\title{
Analysis of Student Thinking Ability in the Topic of Probability: A Descriptive Study of Gender and Math Ability
}

\author{
Rita Raya ${ }^{1, *}$, St. Suwarsosno², Agung Lukito ${ }^{3}$ \\ ${ }^{1}$ Doctoral Program in Mathematics Education, State University of Surabaya, 60213, Surabaya, Indonesia \\ ${ }^{2}$ Department of Mathematics Education, Sanata Dharma University, 55281, Yogyakarta, Indonesia \\ ${ }^{3}$ Department of Mathematics Education, State University of Surabaya, 60213, Surabaya, Indonesia
}

Received September 12, 2020; Revised November 10, 2020; Accepted November 19, 2020

\section{Cite This Paper in the following Citation Styles}

(a): [1] Rita Raya, St. Suwarsosno, Agung Lukito, "Analysis of Student Thinking Ability in the Topic of Probability: A Descriptive Study of Gender and Math Ability," Universal Journal of Educational Research, Vol. 8, No. 12A, pp. 7443 7454, 2020. DOI: 10.13189/ujer.2020.082528.

(b): Rita Raya, St. Suwarsosno, Agung Lukito (2020). Analysis of Student Thinking Ability in the Topic of Probability: A Descriptive Study of Gender and Math Ability. Universal Journal of Educational Research, 8(12A), 7443 - 7454. DOI: 10.13189/ujer.2020.082528.

Copyright $\bigcirc 2020$ by authors, all rights reserved. Authors agree that this article remains permanently open access under the terms of the Creative Commons Attribution License 4.0 International License

\begin{abstract}
The probability is very closely related to everyday life that includes a probabilistic situation. This situation contains an element of uncertainty when someone is thinking about a problem that has various possibilities or consists of a part of luck, then that person is thinking probabilistically. The purpose of this study is to analyze the mathematical probability thinking skills of senior high school students in the response aspect with gender and mathematical abilities. This type of research is a qualitative descriptive study based on five stages, namely (1) natural design, (2) descriptive data, (3) attention, (4) data processing, and (5) the main focus of research. The research was conducted at Senior High School in Jayapura, Indonesia. The research subjects were students of class XI Science. The research instrument consisted of mathematical ability test sheets, probability problem-solving tasks, interviews. The results of the investigation show that the profile of male students' probabilistic thinking on mathematical abilities in solving probability problems includes providing statistical responses in solving probability. Issue is related to the sample space (representatives formation) because it uses a combination to calculate the number of members of the sample space by providing the right reasons. Meanwhile, for women, the profile of probabilistic thinking is using several strategies in solving probability problems related to the sample space (representatives formation). Based on the
\end{abstract}

investigation of the results shows that there are differences in mathematical ability between male and female students probability of problem-solving.

Keywords Gender, Mathematical Ability, Probability, Mathematics Learning

\section{Introduction}

Mathematics is a universal language that allows people to think record and communicate ideas about elements and quantities at all times. The value of thinking skills will have an impact on life because it is very dependent on human thinking skills to survive and adapt to the environment. Various aspects required to help both of these thinking skills, one of which is the mathematical aspects. Mathematical skills are required to help activities, whether in the living system or the education system. The role of mathematics has a significant impact on the development of the mindset of an individual or an student. The value of mathematics is strengthened by the activism and content obtained. One of the mathematical intelligence needed by a student is probabilistic thinking [1].

Probabilistic thinking is closely related to solving a 
problem. Papaieronymou [2] \& Pfannkuch [3] that probabilistic thinking includes how a model is used to describe random phenomena, how data are generating to estimate an opportunity, how other properties of a given situation determine the probability of that situation, also includes being able to understand and use context when solving problems. Savard [4] \& English [5] say that probabilistic reasoning considers the variability of results and random things which are two crucial components.

Batanero et al. [6] \& Schoen [7] stated that at the primary and secondary school level, probability and statistics are part of the mathematics curriculum. The same thing was said by Nikiforidou \& Pange [8]; Jones et al. [9] that probability is an essential part of many mathematics curricula around the world, even in preschool education. The current national curriculum in Indonesia is the 2013 curriculum (K-13) also includes the topic of statistics and opportunity as part of mathematics courses. Statistics and options are formally studying for the first time when students sit in class VII, semester 2. Statistics subject matter and opportunities are then analyzed when students sit in class XI semester 1 . The subject matter of statistics and options contains some of the daily problems faced by students in the form of the issues having probabilistic situations. In solving these problems, a person needs to reason or think to make decisions. The degree a person believes about the possibility of an event occurring largly determined by the presence or absence of knowledge about the event.

Learning should not only focus on the subject alone. However, it must be actively continued in a dynamic way in which students are allowed to explore real-world problems and challenges in order to gain a deeper understanding and context. Learning should not only concentrate on the subject alone. However, it must be actively pursued in a creative manner in which students are allowed to explore real-world problems and challenges in order to gain more profound knowledge and context [10].

As for probabilistic thinking, Jones et al. [9] note that the term probabilistic thinking using to characterize the thought of children in response to circumstances of probabilistic. A person's ability to respond to probabilistic situations varies. A person's ability to react to probabilistic conditions varies. It is following the opinion of Kvatinsky \& Evan [11] say that in the same situation, different people will also respond differently. The response given is influenced by the differ knowledge each person has about the situation and a person's ability to understand the information provided by the problem. Sharma [12] explores the ideas of 14-16-year-old students in dealing with probabilistic situations, especially on fair opportunities for events. Based on the results of the analys, Sharma [12] identifies four categories of probabilistic student thinking based on student responses, namely: non-response, non-statistical responses, partial-statistical response, and statistical responses.

The results of a high school student's preliminary observations in Jayapura City to get an initial impression of the probabilistic thought of the students in solving probability issues. The task given to students is related to the sample space, namely the problem of forming representatives and related to the probability of an event, namely the issue of the child's birth order. After the students answered the assignment in writing, then an interview was carried out so that it could be known more in the students' probabilistic thinking in solving the problem.

Based on the results of the interview, it was revealed that in solving these problems, students gave statistical responses because they used a combination of reasons. Members of representatives that were forming could not be the same as other representatives members even though their positions were different. It could not be a representation consisting of the same people. In this case, students justify their reasoning by using a combination. After knowing the formula used, the student's next strategy is to calculate the number of representatives that can be formed by each group using a combination formula. Then compare the results to decide the correct answer, namely that there are many ways to make Representatives Group A the same as Group B. In solving this problem, students use representations in the form of terms related to probability (combinations, available elements, elements taken, regardless of order) and use letter symbols to represent people.

One of the factors that cause differences in math ability is the difference in physical shape between the male brain and the female brain, where overall, the female brain is smaller than the male mind. The lower parietal lobe of men is more extensive than in women. The size and shape of the different brain automatically distinguish between male and female. It is following the opinion of Jensen [13] which states that these structural differences can result in differences in behaviour, development and cognitive processing between men and women-thus resulting in differences in student learning outcomes because learning outcomes are influencing by behaviour, cognitive development and processing. On the other hand, a person's behaviour, development and cognitive-processing are also affecting by socio-cultural aspects. It is by the opinion of Wang [14], which states: "Broader socio-cultural factors also influence individual differences in cognitive capacity and motivation". in this case, social influence not stated explicitly, so it is possible that gender factors also influence it. Gender is a characteristic that distinguishes men and women both biologically, in behavioural and mental values which are formed by the presence of social and cultural factors. According to Keitel [15], gender is one of the factors that influence the conceptualization process in learning mathematics. So that differences in probabilistic thinking of each individual are 
not only influenced by mathematical abilities but are also influenced by gender differences.

There are several research findings in education and psychology related to probabilistic thinking and mathematical abilities. Jones et al.[16] showed that students with different mathematical abilities, namely students with high math abilities and low math abilities, also differed in terms of probabilistic thinking. In this line with the research results of Polaki [17] \& Sari [18] show that the probabilistic thinking of students with high mathematical abilities is different from the probabilistic thinking of students with low math abilities.

Based on the description that has been described, the researcher is interested in studying the analysis of thinking probability of high school students in terms of mathematical abilities and gender. Two things are the focus of this study related to differences in students' mathematical abilities and gender differences. This study is expected to be a source of information regarding the development of science in mathematics, especially in the course of student abilities and gender in developing learning systems.

\subsection{Problem of Study}

The problems studied in this study are related to:

1. What is the profile of female students' probabilistic thinking with math ability in solving probability problems?

2. What is the profile of male students' probabilistic thinking with mathematical abilities in solving probability problems?

\section{Materials and Methods}

\subsection{Types of Research}

This research is a qualitative descriptive study. This research was conducted by assigning probability problem solving (TPMP) related issues to the sample space (representatives formation) and the probability of an event (birth order). To achieve the intended goal, the researcher conducted an in-depth exploration through interviews with four high school students.

\subsection{Research Subject}

This research was conducted in Jayapura City. The research subjects were students of class XI IPA. Researchers chose senior high school class XI subjects because the material about probability or opportunity has been taught based on the mapping of the mathematics curriculum. In addition, students of class XI are considered communicative enough and are assumed to have sufficient knowledge to be interviewed to investigate and reveal probabilistic thinking in solving probability problems.

\subsection{Research Instrument}

The researcher himself becomes the main instrument in this research because the researcher himself plays a significant role in all research processes and cannot be represented by other people. Researchers act as planners, data collectors through in-depth interviews directly with research subjects, analysts, interpreters, and report the results of research. The supporting instruments used by the researcher include math ability tests, probability problem-solving tasks, and interview guides.

\subsection{Data Collection Technique}

The data collection procedure in this study follows:

1. Subjects were giving TPMP questions to solve by writing down what the subject thought. Several days later, an in-depth interview was conducted regarding the aspects of probabilistic thinking until the first data were obtaining.

2. After a few weeks, the subjects were given the same TPMP questions to be resolve while a second interview was conducted regarding aspects of probabilistic thinking until the second data were obtained.

3. The data collected from the subject were examined for consistency by comparing the first data with the second data. If there inconsistent data, then another interview is conducted until third data are obtaining.

4. The next step is to examine the consistency of the data obtained; namely, the first data reviewed with the third data. If consistent, then the second data is reviewed with the third data. If the second data and the third data are inconsistent, then the first data are analyzed.

\subsection{Data Analysis Technique}

The data collected from the interviews were analyzed to answer research questions. Data analysis includes: data reduction, categorization or classification of data, interpretation or interpretation of data and drawing conclusions

\subsection{Research Procedure}

In this research, the research procedure steps are as follows :

\section{Preparation Stage}

At this stage the researcher examines the theory related to probabilistic thinking by conducting literature studies from various sources; prepared supporting instruments 
which include TKM instruments, TPMP, and interview guide instruments; and perform instrument validation.

\section{Implementation Stage}

The activities at this stage are: selecting subjects by giving TKM and grouping subjects into groups of mathematical abilities based on the results of tests of mathematical skills; giving TPMP to each issue; and conduct task-based interviews with four selected subjects.

\section{Data Analysis Stage}

At this stage, data analysis consists of data reduction, data categorization, data interpretation, concluding data/drawing conclusions, then describing the student's probabilistic thinking profile to answer research questions.

\section{Results of Investigations}

\subsection{Results of Analysis the Mathematical Ability of Male Subjects with Probability Problems}

\subsubsection{SLT Strategy Category in Completing}

This section will describe the results of data analysis in the first and second categories which reveal the types of strategies used by SLT when solving problem probability problems. The results of the interview showed four categories indicating the method used by SLT, namely: identify problems, use combinations to calculate the many kinds of representatives that can be formed, do not use permutations to calculate the many different types of representatives that can be created, and decide by comparing the results of the calculations of the two groups.

\section{a. Identifying Problems}

From the results of the analysis in the first and second categories, it was revealed that the strategy categories used by SLT in determining problems consisted of two sub-categories, namely: mention the number of representatives members in Group A and Group B. They want to be formed and state the questions asked. It was revealed from an interview with SLT as in the following interview excerpt:

So there are two groups, each group consisting of 10 people. Group A wants to create representatives of 2 people chosen from 10 people. Meanwhile, Group B wants to make representatives of 8 people, which was taken from 10 people. (W1LT (1) 003)

Which one asked which statement is correct. Information a: many kinds of representatives formed by Group A are smaller than Group B. (W1LT (1) 004)

Which $b$, the many different types of representatives created by Group A are the same as Group B.
Which $c$, the many kinds of representatives formed by group A are bigger than Group B (W1LT (1) 005)

\section{b. Using Combinations}

From the results of data analysis in the first and second categories, it revealed that the strategy category used a combination to calculate the many kinds of representatives that could be forming consisting of three sub-categories, namely: using combinations, counting the many different types of representative Group A could create, and measuring the many different kinds of representatives Group B could form.

From the interview results, it showed that SLT used a combination to solve this probability problem (W1LT(1)006). According to the SLT, the representatives that Group A and Group B want to form must not have the same members. They cannot all be members of representatives with other representatives even though the order is different. In other words, SLT thought that the representatives that the two groups wanted to form ignored order, just like the combination. Hence, SLT decided to use a combination formula.

After knowing the enumeration rules to be used, then what SLT did was count the many kinds of representatives that could be formed by Group A and Group B using a combination. The following is a snippet of the interview :

$P$ : In this case, how much is $n$ ?

S: For Group A, the $n$ is 10.

$P$ : How much for the $k$ ?

S: $\quad$ Here the $k$ is 2.

$P$. How do you count the number of representatives that can be formed?

S: How .......(writing):

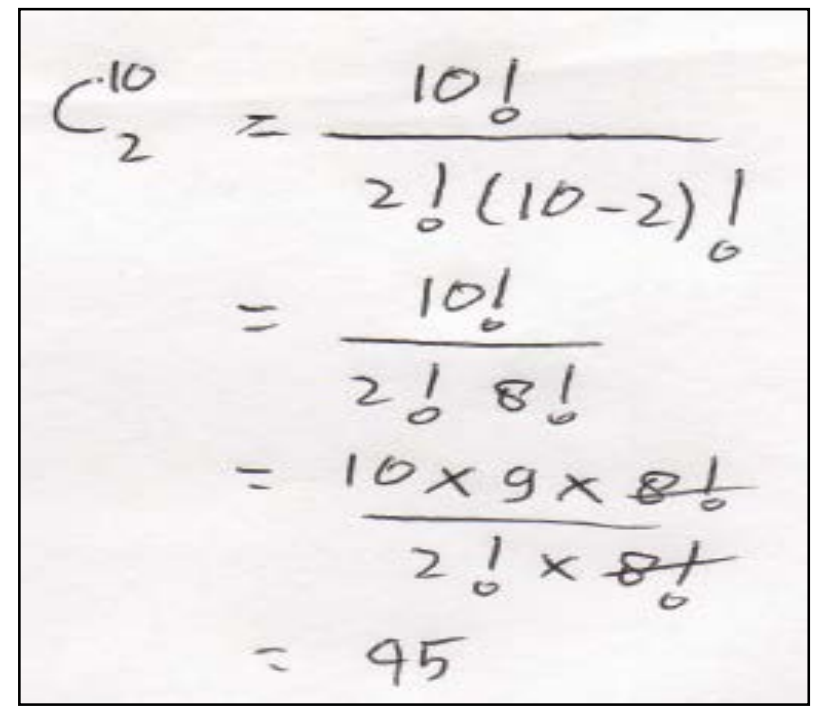

Figure 1. The results of students' answers in terms of using combinations

\section{c. Not Using Permutations}

From the results of data analysis in the first and second 
categories, it explained that the strategy category did not use permutations to calculate the many kinds of representatives that could be created consisting of two sub-categories, namely: does not use permutations and the reason the subject does not use permutations.

From the interview results, it was tell that SLT understood the use of permutations and also understood what the questions wanted. Therefore, SLT does not use permutations to solve this probability problem. This understanding of SLT can be observed from the reasons for not using the permutations described by SLT. The following are the excerpts from the interview:

... For permutations, the order should be considering. For example $(1,2)$ cannot be equal $(2,1)$. That is why I do not use permutation here. (W1LT (1) 025)

$P: \quad$ Why not use permutations?

S: $\quad$ Permutations are not suitable for this problem.

$P$ : Why doesn't it match?

Because if the permutation is the order, you pay attention to it, whereas in this matter yourself want to form representatives with two members

s: and eight members. Two people are just random; the order is not considered as before $(1,2)$ is the same as $(2,1)$. So permutations do not match. Perfect combination. (W1LT (1) 027-28)

Here I do not use permutation because the representatives that are going to be creating is random; it does not pay attention to order. (W2LT (1) 034)

\section{d. Deciding by Comparing Calculation Results}

From the results of data analysis in the first and second categories, it was shown that the strategy category used by SLT was to decide by comparing the results of calculations in the two groups. This category consists of two sub-categories, namely: compare the calculation results of Group A with Group B and decide that the many kinds of representatives that can be formed by Group A are the same as Group B.

From the interview result, it revealed that knowing the many representatives that can be formed by each group and based on the questions on the questions (W1LT (1) 004-005), SLT then compared the results of the calculations of the two groups. Based on the results of analyses using a combination, SLT decided to choose answer $b$ because the two groups could form the same representatives, namely 45 kinds of representatives. The following is a snippet of the interview :

From the results of calculations with a combination, Group A can form 45 representatives and Group B also 45 representatives. Because Group A and Group $B$ can both create 45 different representatives, the correct answer is answer b. (W1LT (1) 043)
If I compare the two groups, the results are the same, namely that both groups can form 45 different representatives. So the correct answer is answer $b$ : many kinds of representatives that can be created by Group A are the same as Group B. (W1LT (1) 114)

\subsubsection{SLT Representations Category in Resolving}

This section will describe the results of data analysis in the first and second categories which reveal the types of representation used by SLT when solving the probability problem of question 1 . The results of the interview showed five categories that indicate the term used by SLT, namely:

\section{a. Using Terms Related to Probability}

From the results of data analysis in the first and second categorizations, it was told that the representation category in the form of the use of terms related to the probability used by SLT consisted of six sub-categories, namely: mentioning the term combination, mentioning available element terms, mentioning the term elements taken, saying terms without pay attention to sequence, mention permutation terms, and mention terms pay attention to series.

During the interviews, SLT repeatedly mentioned the combination terms, the elements available, and the details are take to be applied in calculating the many kinds of representatives that can be formed by the two groups. The following are excerpts from the interview:

I finished this by using a combination. (W1LT (1) 006)

The symbol of the combination is: C. (W1LT (1) 012)

$n$ is all the elements that exist. (W1LT (1) 013)

$k$ is the element taken from $n$. (W1LT (1) 014)

It shows that SLT understands the use of combinations and permutations, so it can help SLT in solving this probability problem.

\section{b. Using Number Symbols}

For each group, SLT uses numerical initials to express people's names so that they are more uncomplicated and more comfortable to remember. So it can be said that the use of this symbol can help SLT in solving problems. The following is an excerpt from the interview with SLT :

$P$ : How do you create representatives?

s. For Group A, suppose (write): 1, 2, 3, 4, 5, 6, 7,

S: $\quad 8,9,0$.

P: What do the numbers represent?

$S$. The numbers represent the members of Group

S: A.

P: What do you mean?

S: Members in Group A which consists of 10

S: people.

P: Ooo, so show people? 
Yes. Number 1 is the first person, number 2 is

$S: \quad$ the second person, number 3 is the third person, and so on the number 0 is the tenth person.

$P$ : Why don't you just use someone's name?

S: $\quad$ I use numbers to make it easy, simpler. If you use a long name later. (W1LT (1) 047-051)

c. Using Number Symbols

The results of the interviews revealed that SLT used a tree diagram to list the kinds of representatives that could be formed by the two groups (W1LT (1) 046). For that, SLT drew nine tree diagrams. In the first diagram, SLT registers by pairing the number 1 (first person) with other numbers (second person to the tenth person). The following is an excerpt from the interview with SLT:

$P$ : How do you do it?

$S$ : It is the first person later paired with the others

$S: \quad$ (making a tree diagram)

$P: \quad$ What are the results?

The results are first-person with a second person (writing: 1, 2), the first person with a

$S: \quad$ third person (writing: 1, 3), the first person with the fourth person (writing: 1,4) and until the first person with the tenth person (writing: 1,0 ) as below.

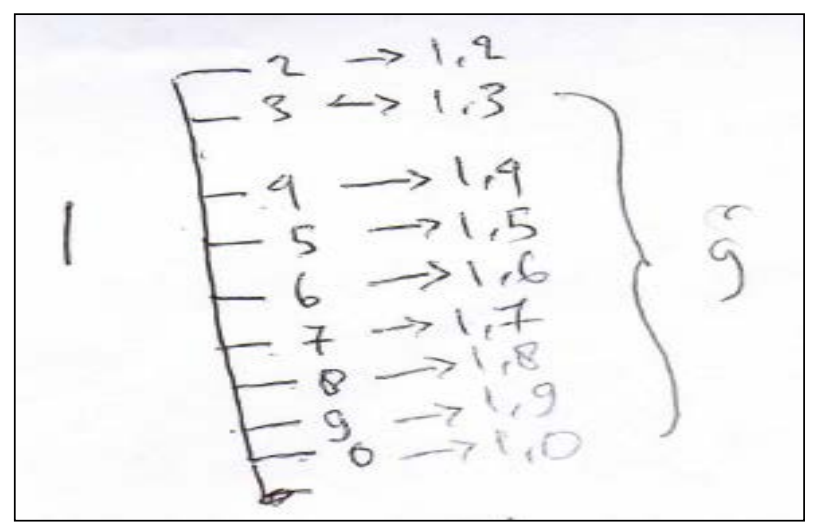

Figure 2. Results of students' answers in terms of using tree diagrams

d. Explain the Rules for Forming the Various Representatives

From the results of the interview, it was reported that several rules were used by SLT to form various representatives in Group A, namely: the representatives must have two members and the members of representatives cannot be the same as other representatives members. Here are some excerpts from the interview:।

The rule is that members of the representatives cannot be the same person, as before 1 to 1 because the representatives that want to be completed must have two members instead of 1 person. (W1LT (1) 080)

... Cannot have a two-member representative consisting of himself. So he has to be with another friend ... ( $\left.W_{2} L T(1) 055\right)$

I cannot repeat the writing of existing representatives like earlier representatives 2 and 1; I did not write again because they were the same as representatives one and two that already existed.

Even though the positions are different, the people on the representatives are the same. (W1LT (1) 081)

Whereas in Group B, according to SLT, the rules for the formation of the various representatives are the same as the rules for the construction of the multiple representatives in Group A, namely that the representatives cannot have the same members. It cannot form a new representative whose members are already on the representatives. Previous the following is a snippet of the interview.

The rules are the same as for two-member representatives: there cannot be the same person on the same representatives, and there cannot be representatives whose members are all the same as other representatives even though their positions are different. (W1LT (1) 100)

The rules described by SLT above show their understanding of informing various representatives in Group A and Group B so that they can help SLT to solve problems.

e. Describing an Event that may or may not have
happened

From the results of data analysis in the first and second categories, it was explain that the representation category in the form of an explanation of an event that may or may not occur by SLT consists of seven sub-categories, namely: explain the reasons for not including $(2,1)$ as one of the representatives in Group A, explain the reasons for not including $(3,1)$ as one of the representatives in Group $A$, explain the reasons for not including $(3,2)$ as one of the representatives in Group A, explaining the reasons for not including $(1,1)$ as one of the representatives in Group A, explaining the reasons for not including $(2,2)$ as one of the representatives in Group A, explaining the reasons for not including $(4,5,7,1,3,2,8,6)$ as one of the representatives in Group B, explaining the reasons for not including $(9,2,5,6,3,1,7,4)$ as one of the representatives in Group B

\subsection{Results of Analysis the Mathematical Ability of Male Subjects with Probability Problems}

From the results of the interviews, it was told that the SPT uses a combination to solve this probability problem. SPT understands the use of combinations and also understands what the questions want. It can be noticed from the reasons for using the combination is described by 
SPT as revealed in the following interview excerpt:

P: How do you solve or answer that question?

$S: \quad$ The way I answer is using a combination.

$P$ : Why do you use a combination?

Because according to the questions, two people will be chosen. So the two people cannot be two

$S:$ people the same again. So, the combination matches. (W1PT (1) 005-06)

$P$ : What do you mean?

Question 2 people. Thus, the combination is

s. more suitable, because if the combination is $A B$ $=B A$. For permutation, $A B$ is not the same as BA. (W1PT (1) 005-007)

\subsubsection{SPT Strategy in Completion}

In this section describes the results of data analysis on the first and second categorizations, which reveal the categories of strategies used by the SPT when solving the probability problem 1 . The results of the interview showed four categories indicating the method used by the SPT, namely: identify problems, use the combination formula to calculate the number of representatives that can be formed, do not use the permutation formula to calculate the number of representatives that can be created, and decide by comparing the calculation results of the two groups.

\section{a. Identifying Problems}

From the results of data analysis on the first and second categories, it was revealed that the strategy categories used by the SPT in identifying problems consisted of two sub-categories, namely: mentioning the number of representative members in Group A and Group B who wanted to be formed and mentioning the things that were asked. It was reported from an interview with SPT as in the following interview excerpt:

It knows that Group A wanted to form representatives in which the representatives had two members chosen from 10 people. However, for Group B, he wanted to create a representative of 8 people who were selected from 10 people. (W1PT (1) 003)

What asking between the two groups, which one is more or less the number of representatives formed or both are the same? (W1PT (1) 004)

\section{b. Using Combinations}

From the results of data analysis in the first and second categorizations, it exhibited that the strategy categories use a combination to calculate the number of representatives that can be formed consisting of four sub-categories, namely: using a combination, the reason for the subject using a combination, calculating the number of representatives that can be created by Group A, and counting the number of representatives that can be formed-formed by Group B.

From the results of the interview, it was revealed that the SPT used a combination to solve this probability problem (W1PT (1) 005). According to the SPT, the representatives that Group A and Group B want to form cannot have the same members and cannot be the same as other representatives even if the order is different. In other words, the SPT thought that the representatives the two groups wanted to form ignored order, just like the combination, so the SPT decided to use a combination formula.

After knowing the enumeration rules that will be using, then what the SPT does is counting the many kinds of representatives that can be formed by Group A and Group $\mathrm{B}$ using a combination. The following is a snippet of the interview.
$P: \quad$ In this case, how much is $n$ ?
S: $\quad$ For this problem, then it is 10 .
$P$ : How much for $r$ ?
S: $\quad$ For Group A, $r$ is 2.
$P$ : How do you count the number of representatives
$P: \quad$ that can be formed?
S: $\quad$ The method is like this (writing):

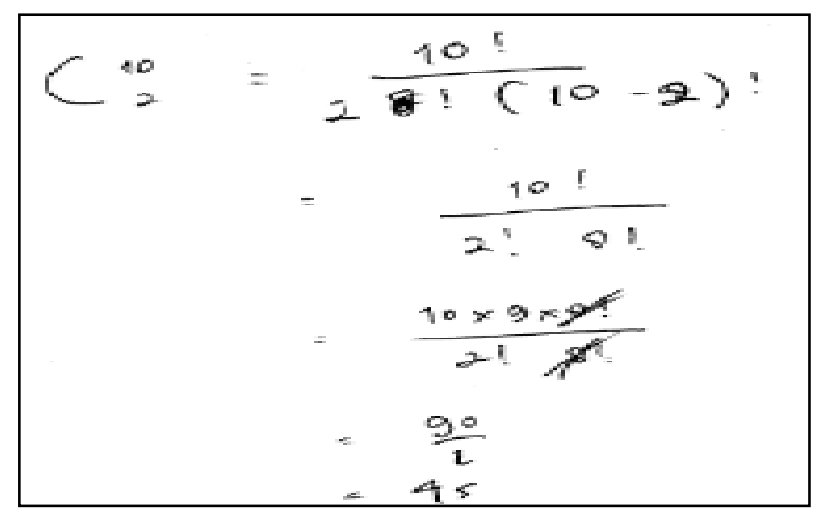

Figure 3. Results of female answer

\section{c. Not Using Permutations}

From the results of data analysis in the first and second categorizations, it showed that the strategy category does not use permutations to calculate the many kinds of representatives that can be formed consisting of two sub-categories, namely: not using permutations and the reason for the subject not using permutations.

From the results interview, it exposed that the SPT understood the use of permutations and also understood what the questions wanted. Therefore, the SPT does not use permutations to solve this probability problem. This understanding of the SPT can be seen from the reasons for not using the permutations described by the SPT. The following are the excerpts from the interview:

$P$ : Why don't you use permutations?

S. I do not use permutations, because this problem

S: $\quad$ is more suitable using combinations. 
P: What do you mean?

If the permutations are in order, the order is considering. As for the question, we want the form of representatives with two members, so

$S: \quad$ that the order is not reflect. The important thing is that there are two members. So it is not suitable to use permutations. (W1PT (1) 022-23)

\section{d. Deciding by Comparing Calculation Results}

From the results interview it revealed that knowing the many kinds of representatives can be formed by each group and based on the questions on the questions (W1PT (1) 004), the SPT then compared the results of the two groups (W1PT (1) 108). Based on the results of calculations using a combination formula, the SPT decided to choose answer b because the two groups could form the same representatives, namely 45 kinds of representatives. The following are excerpts from the interview:

So if I compare the two groups, because the calculation results with the combination are the same, then here I choose answer $b$ : the many kinds of representatives that can be set Group A are the same as Group B. (W1PT (1) 108)

I chose answer $b$ because from the calculation with the combination when compared to the two groups $A$ and $B$; the results are the same. Namely, 45 kinds of representatives can be completed in each group. (W1PT (1) 114)

\subsubsection{SPT Representations Category in Resolving}

\section{a. Using Terms Related to Probability}

Based the results of data analysis in the first and second categorizations, it showed that the representation category in the form of the use of terms related to the probability used by the SPT consisted of six sub-categories, namely: mentioning the term combination, mentioning the available element terms, mentioning the term elements taken, saying phrases without pay attention to sequence, mention permutation terms, and mention terms pay attention to series. During the interviews, the SPT repeatedly mentioned the combination terms, the elements available, and the details are taking to be used in calculating the number of representatives that could be formed by the two groups. The following are excerpts from the interview:

The way I answer is using a combination. (W1PT (1) 005)

$C$ is the symbol of combination. (W1PT (1) 010) If $n$, the number of different elements available. (W1PT (1) 011)

$r$ is the number of factors taken from the $n$ available elements. (W2PT (1) 014
During the interviews, SPT also mentioned the terms without paying attention to the order to show understanding of the using combinations and relationship with the formation of various representatives in both groups. The SPT said that problem solving, a combination was used because the questions implied that the representatives' Group A and Group B wanted to form ignored order, the same as the combination.

\section{b. Using the Capital Letter Symbol}

From the results of data analysis in the first and second categories, it announced that the representation category in the form of capital letter symbols used by the SPT consisted of two sub-categories, namely utilizing the letter A-J symbol to state the names of 10 people and the reason for the subject not using people's names.

During interviews, the SPT repeatedly emphasized that to list the kinds of representatives that each group can form, the SPT uses capital initials to state people's names. It began because according to the SPT, the use of people's names was too long, so it would be difficult for them to form representatives. So it can be said that the use of this symbol can help the SPT in solving problems. The following is an excerpt from the interview with the SPT:

P: How do you create representatives?

S. Can with tables. Suppose that ten people: $A, B$,

S: $\quad C, D, E, F, G, H, I, J$

P. What do the letters $A, B, C, D, E, F, G, H, I, J$ represent?

S: $\quad A, B, C$ to J represent the names of the people.

$P$ : Why not just use someone's name?

I use initials, do not employ people's names. If

S: you use a person's name, it will be long and challenging to make it (W1PT (1) 026-028)

c. $\quad$ Using Tables and Tree Diagram

From the results of data analysis in the first and second categorizations, it was reported that categories used tables and tree diagrams to list the types of representatives that can be formed by Group A consisting of two sub-categories, namely: using tables to record the various representatives in Group A and using diagrams to lists the multiple representatives in Group A.

Results of the interview, it revealed that SPT used a table list as many as 45 kinds of representatives that could be formed by Group A (W1PT (1) 053). According to the SPT, all those located on the diagonal did not include representatives because they had one member. SPT says if we elect all those are different above the diagonal as representatives, then all those who are below the diagonal do not include the representatives. Vice versa (one student female), representatives on the left of the diagonal are the same as the representatives on the right diagonal. 


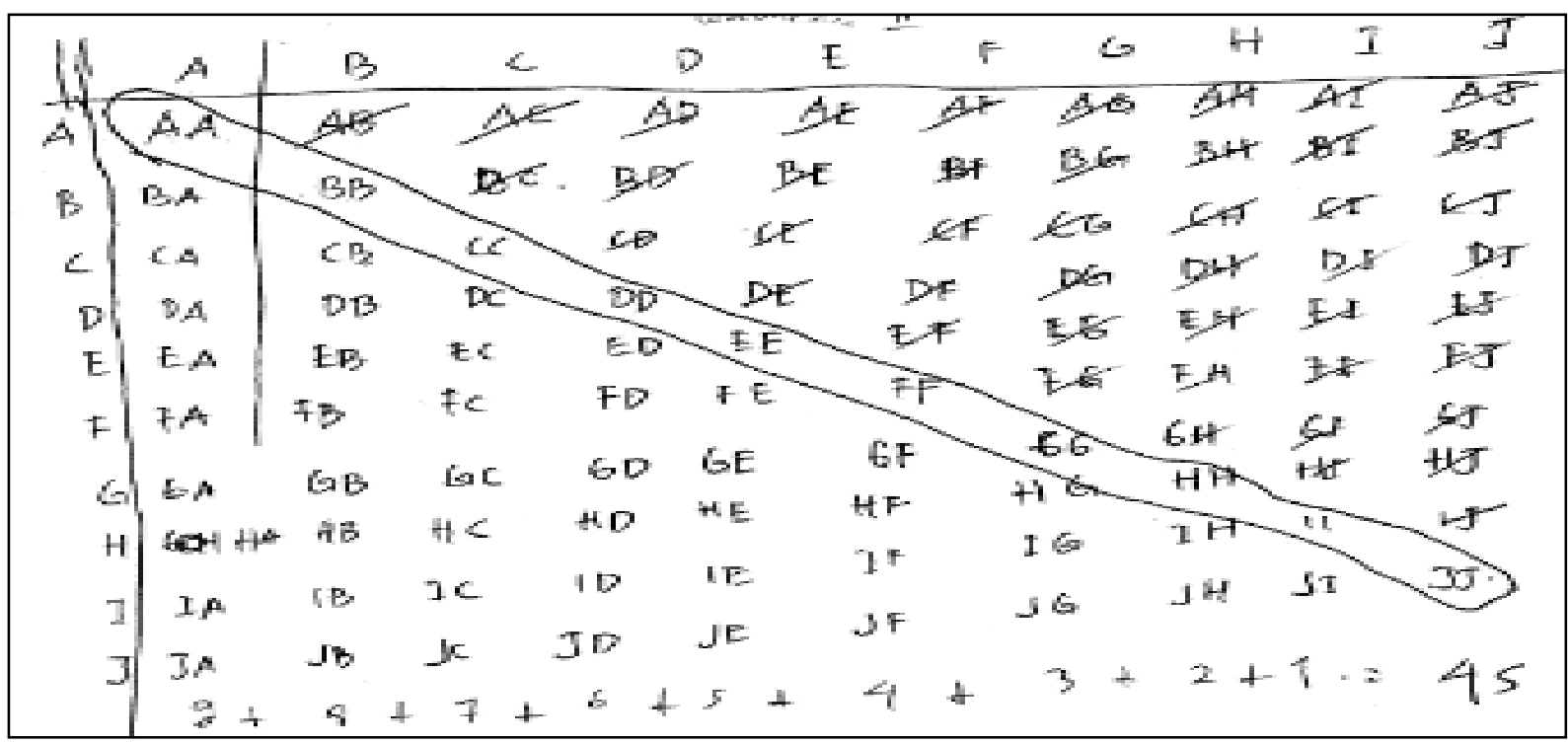

Figure 4. The results of solving women's questions on the aspects of the use

d. Explain the Results for Forming the Various Representatives

Results of data analysis in the first and second categorizations, it was revealed that the representation category in the form of an explanation of the rules forming the various representative used by the SPT consisted of three sub-categories, namely explaining the practices for creating various representatives using tables in Group A, defining the rules for forming various representatives using a tree diagram in Group A, and explain the rules for creating various representatives in Group B.

Based on the interviews revealed some of the rules used by the SPT to form representatives. To create representatives in Group A using a table, then everything on the diagonal does not include the representatives because it consists of one person. SPT says if we choose all those are different above the diagonal as a representative, then all those are next to the diagonal do not include the representatives. Vice versa (one student female) representatives on the left of the diagonal are the same as the representatives on the right diagonal. The following is a snippet of the interview:

$P: \quad$ Which of the tables is not a representative?

S. It AA, BB, CC until JJ does not enter. (Mark AA through $J J)$

P: Why?

s. Because AA, BB to JJ are the same people in one representative.

$P$ : What do you mean?

$A A, B B$ to JJ are the same person in the same representatives so that there is only one person,

$S: \quad$ while in the questions it is said that there are two members. So everyone with one member will not be on the representatives, because the representatives must have two members.

P: Any else?

S. Everything above the diagonal does not enter (cross out the right side of the diagonal)

P: Why was it crossed out?

I have crossed out because it is the same as the s. one below (pointing at the left side of the diagonal) that I have chosen. So just pick one side. (W1PT (1) 47-51)

The rules described by the SPT above show its understanding of informing various representatives in Group A and Group B so that they can help the SPT to solve problems.

e. Describing an Event that May or May Not Have Happened

Based the results of data analysis in the first and second categories, it was revealed that the representation category in the form of an explanation of an event that may or may not occur by the SPT consists of 10 sub-categories, namely: explaining the reasons in the table for not including $\mathrm{AB}$ as one of the representatives in Group $\mathrm{A}$, explaining the bases in the table not including $\mathrm{AC}$ as one of the representatives in Group A, explaining the reasons in the table not including $\mathrm{BC}$ as one of the representatives in Group A, explaining the reasons on the tree diagram not including BA as one of the representatives in Group A, explaining the reasons in the tree diagram not including CA as one of the representatives in Group A, explaining the bases in the tree diagram for not including $\mathrm{CB}$ as one of the representatives in Group A, explaining the reasons for not including $\mathrm{AA}$ as one of the representatives in Group A, explaining the reasons for not including BB as one of the representatives in Group A, explain the reasons for not entering DEGACBFH as one of the representatives 
in Group B, explain the reasons for not including CHDJEFIG as a representatives in Group B.

\section{Discussion}

The results of the investigation of high school students' math abilities in solving questions related to the topic of probability vary widely. The answers obtained from the gender differences between men and women provide a significant difference in solving the problems given. It is evident from the results of the study contained in the investigation results section.

Then, male subjects used several strategies in solving probability problems related to the sample space (representatives formation), namely identifying issues by paying attention to what was known and what was asking about the questions. He used the strategy of thinking that the members of the sample room that were formed could not consist of the same person and that the members of a sample room could not all be the same as the other members of the sample room. So he used combinations and did not use permutations to count the number of sample space members. He compared the results of the two groups' calculations to decide the correct answer. Meanwhile, to solve problems related to the probability of an event (the order of the child's birth). He identifies the problem by paying attention to what is known and what the questions are asking. He uses coins because according to him, the coin draw event and birth order both have two sides then counts the number of sample room members in the drawing of 2 coins. Three coins and a family with three children so that he can find a general formula that can be used to calculate the number of room member sample. He used the recipe found to calculate the number of members of the sample space.

Furthermore, male subjects used multiple representations in solving probability problems related to the sample space (representatives formation). He uses representations in the form of terms related to probability such as combinations, available elements, elements taken, without regard to order, paying attention to sequence, and permutations. He used tree diagrams to list members of the sample room and used number symbols to express people's names to make it simpler and easier to remember. Besides, he uses representations in the form of explanations of rules forming members of the sample space and describes an event that may or may not occur, which shows his understanding informing members of the sample space. Meanwhile, to solve probability problems related to the probability of an event (childbirth order), he uses representations in the form of a square pattern to calculate the number of members of the sample space. He uses terms related to probability such as many possibilities, many sides, and many coins or many people, odds, and many events. He uses a tree-diagram representation to list the various members of the sample space and uses fractions to express the probability of a birth order occurring.

It is a tabular comparison with the results found for the female gender. The female subject gave a statistical response in solving the probability problem related to the sample space (representative formation) because it used a combination to count the number of members of the sample room by providing the right reasons. Those, she can justify his reasoning using a combination. In addition, he is also able to register the members of his sample room. She also provides a statistical response because he found a formula and uses it to calculate the number of space members. She is also able to register her sample room members. She used classic definitions to calculate the probability of each event occurring by providing the correct explanation. It means that he can justify his reasoning using classical interpretations.

On the other hand, female subjects used several strategies in solving probability problems related to the sample space (representatives formation). He identifies problems by paying attention to what is known and what is asking about the questions. He used the strategy of thinking that the members of the sample room that were formed could not consist of the same person and that the members of a sample room could not all be the same as the other members of the sample room, so he used combinations and did not use permutations to count the number of sample space members. He compared the results of the two groups' calculations to decide the correct answer. Meanwhile, problem-solving of probability related to the probability of an event (the order of the child's birth), She identifies the problem by paying attention to what is known and what the questions asked.

Female subjects use multiple representations in solving probability problems related to the sample space (representatives formation). She uses representations in the form of terms related to probability such as combinations, available elements, elements taken, without regard to order, paying attention to sequence, and permutations. She used capital letters to express people's names to make it easier for him to register various representatives. She uses tables and tree diagrams to list the multiple members of the sample room. Besides, she uses representations in the form of explanations of rules forming members of the sample room and a description of an event that may or may not occur.

Meanwhile, to solve probability problems related to the probability of an event (childbirth order), She uses a representation in the form of a square pattern to calculate the number of members of the sample space. She uses terms related to probability such as many possibilities, many sides, many coins or many people, many events, and odds. She uses tree diagrams to list members of his sample space and uses fractions to express the probability of an event occurring. 
Table 1. Differences in Probabilistic Thinking Profiles of Male and Female Subjects With High Mathematical Ability in Solving Probabilistic Problems

\begin{tabular}{ll}
\hline \multicolumn{1}{c}{ The subject is male math ability. } & \multicolumn{1}{c}{ The subject is female math ability. } \\
\hline $\begin{array}{l}\text { The probability of an event. The male subject with high math } \\
\text { ability adds the strategy of calculating the number of members of } \\
\text { the sample room in a family with three children to find the formula }\end{array}$ & $\begin{array}{l}\text { The probability of an event. The female subject with high math } \\
\text { abilits a strategy of calculating the number of members of the }\end{array}$ \\
$\begin{array}{l}\text { used to calculate the number of members of the sample room in } \\
\text { solving problems related to the probability of an event (childbirth }\end{array}$ & $\begin{array}{l}\text { to calculate the number of members of the sample room in solving } \\
\text { problems related to the probability of an event (childbirth order). }\end{array}$ \\
$\begin{array}{l}\text { order). He also finds the formula that can be used in general to count } \\
\text { the number of sample room members in events containing more }\end{array}$ & $\begin{array}{l}\text { She did not find the formula which can be used in general to } \\
\text { calculate the number of members of the sample space for events } \\
\text { than two sides (e.g. dice draw events). }\end{array}$ \\
\hline
\end{tabular}

Based on what has been describe, male subjects with low math abilities are more analytical thinking and flexible in solving probability problems than female issues. It can be seen when solving the question of the probability of an event; the male subject finds a way that can be used to count the number of members of the sample space, namely by relating it to the coin drawing event. Besides, male subjects with low math abilities also used classical interpretations. In contrast, female subjects with low math abilities used intuitive strategies by performing attribute substitution processes in solving the probability of an event problem.

It is following the opinion of Dagun [19], which states that men's and women's ways of thinking are different, that is, men are more analytical and flexible than women. Likewise, with the opinion of Jensen [18] which states that men generally outperform women in mathematical reasoning. Erdem \& Soylu [20] also said that men are superior to women in mathematical reasoning. The same thing was obtained from the research results of Yenilmez et al.[21] (2005), said that boys have higher scores than girls on proportional reasoning, probabilistic reasoning, and combinational reasoning.

Likewise, the research results of Valanides [22] \& Yenilimez et al. [21] stated that boys have a much higher performance than girls on probabilistic reasoning. The results of this study are also in line with the results of Paul [23] study which states that there is a significant difference in the cognitive level of student probability based on gender, where men have fewer misconceptions than women. Then, the research results of Tsakiridou \& Vavyla [24] show that there are differences in male and female students in probabilistic thinking. Meanwhile, in their study, Sari et al. [25] found that students with high and low math skills had discrepancies in responding to assignments of 1 and 2-dimensional sample space and comparing the likelihood of assigning markers and contextual to drawing. In responding to the contextual likelihood of an occurrence task and the spinner probability comparison task, the representations used by students with high and low math abilities also varied. Meanwhile, in their analysis, Zetriuslita et al. [26] found that both male and female students were already able to generalize the ability to complete the data presented at high levels of ability and were not yet able to recognize and explain concepts and evaluate them. In comparison, male and female students displayed some similarities at medium and low proficiency levels.

Another interesting finding was the subject of men and women in solving the probability of an event (birth order of the child looking for a formula that can be used to calculate many possibilities that birth order can happen because they do not know the procedure. They do not directly calculate many birth orders can occur through a tree diagram for this problem they had never found. For this reason, they use coins for the following reasons: (1) coin draw events and birth order problems are similar because they both have two sides and (2) coin draw events have been studied so that it can help them find the formula they need.

The findings showed that gender had a significant effect on the thinking abilities of students. In terms of thought skills, this study provides evidence that male reflective is better than female and there are variations in the process.

\section{Conclusions}

Based on the results of the investigation concluded that the probabilistic thinking Profile male students and female students in general profiles are relatively similar in solving probability problems. In addition, several representations in solving problems is related to the probability of the sample chamber (committees). They use words in the form of terms related to probability such as combinations, available elements, elements taken, regardless of order, paying attention to sequence, and permutations.

\section{Acknowledgements}

The author would like to thank Cendrawasih University for the financial support provided during the research process. Furthermore, the authors would like to thank the Doctoral Program in Mathematics Education, State University of Surabaya Indonesia for all the facilities provided during this research process.

\section{Appendix}

TPMP: Probability Math Comprehension Test 
TKM: Mathematical Ability Test

SLT: Male Students

W1LT: Subject interview code for male

SPT: Female student

W1PT: Subject interview code for female

\section{REFERENCES}

[1] C. Hikayat, Suparman, Y. Hairun, and H. Suharna, "Design of realistic mathematics education approach to improve critical thinking skills,” Univers. J. Educ. Res., vol. 8, no. 6, pp. 2232-2244, 2020, DOI: 10.13189/ujer.2020.080606.

[2] I. Papaieronymou, “College students' achievement and understanding of experimental and theoretical probability: the role of tasks," 2012.

[3] M. Pfannkuch et al., "Probability modeling and thinking: What can we learn from practice?," Stat. Educ. Res. J., vol. 15, no. 2, pp. 11-37, 2016.

[4] A. Savard, Developing probabilistic thinking: what about people's conceptions?, In: Cherno. Dordrecht: Springer International Publishing, 2014.

[5] L. D. English and J. M. Watson, "Development of probabilistic understanding in fourth grade,” J. Res. Math. Educ., vol. 47, no. 1, pp. 28-62, 2016, DOI: 10.5951/jresematheduc.47.1.0028.

[6] C. Batanero, J. D. Godino, and R. Roa, "Training teachers to teach probability,” J. Stat. Educ., vol. 12, no. 1, pp. 1-15, 2004, doi: 10.1080/10691898.2004.11910715.

[7] R. C. Schoen, M. LaVenia, E. Chicken, R. Razzouk, Z. Kisa, and M. Boylan, "Increasing secondary-level teachers' knowledge in statistics and probability: Results from a randomized controlled trial of a professional development program,” Cogent Educ., vol. 6, no. 1, pp. 1-26, 2019, DOI: 10.1080/2331186X.2019.1613799.

[8] Z. Nikiforidou and J. Pange, "The Notions of Chance and Probabilities in Preschoolers," Early Child. Educ. J., vol. 38, no. 4, pp. 305-311, 2010, DOI: 10.1007/s10643-010-0417$\mathrm{x}$.

[9] G. A. Jones, C. W. Langrall, C. A. Thornton, and A. T. Mogill, "Students' probabilistic thinking in instruction," $J$. Res. Math. Educ., vol. 30, no. 5, pp. 487-519, 1999, DOI: 10.2307/749771.

[10] S. R. Ningsih, Disman, E. Ahman, Suwatno, and A. Riswanto, "Effectiveness of using the project-based learning model in improving creative-thinking ability," Univers. J. Educ. Res., vol. 8, no. 4, pp. 1628-1635, 2020, DOI: 10.13189/ujer.2020.080456.

[11] T. Kvatinsky and R. Even, "Framework for teacher knowledge and understanding about probability,” Dev. a Stat. Lit. Soc. Proc. Sixth Int. Conf. Teach. Stat. (ICOTS 6), vol. ICOTS6, no. 1, pp. 1-6, 2002.

[12] Sharma, "Cultural influences in probabilistic thinking," $J$. ofMathematics Res., vol. 4, no. 5, pp. 53-74, 2012, DOI: 10.5539/jmr.v4n5p63.

[13] E. Jensen, Pemelajaran berbasis otak: paradigma pengajaran baru, (2nd eds). Jakarta: PT. Indeks, 2011.

[14] M. Te Wang and J. L. Degol, "Gender gap in science, technology, engineering, and mathematics (STEM): current knowledge, implications for practice, policy, and future directions,” Educ. Psychol. Rev., vol. 29, no. 1, pp. 119-140, 2017, DOI: 10.1007/s10648-015-9355-X.

[15] P. Valero, "Social justice and mathematics education gender, class, ethnicity and the politics of schooling," ZDM Int. $J$. Math. Educ., vol. 33, no. 6, pp. 187-191, 2001.

[16] G. A. Jones, C. W. Langrall, C. A. Thornton, and A. Timothy Mogill, "A framework for assessing and nurturing young chiedren's thinking in probabieity,” Educ. Stud. Math., vol. 32, no. 2, pp. 101-125, 1997, DOI: 10.1023/A:1002981520728.

[17] M. V Polaki, "Mathematical thinking and learning using instruction to identify key features of basotho elementary students ' growth in probabilistic thinking," Math. Think. Learn., vol. 6065, no. October 2014, pp. 37-41, 2009, DOI: 10.1207/S15327833MTL0404.

[18] D. I. Sari, "Berpikir probabilistik siswa sekolah dasar (SD) dalam menyelesaikan tugas probabilitas berbasis teknologi," J. Pendidik. Mat. APOTEMA, vol. 6, no. 1, pp. 1-11, 2020.

[19] S. M. Dagun, Maskulin dan feminin: perbedaan pria-wanita dalam fisiologi, psikologi, seksual, karier, dan masa depan. Bandung: Rineka Cipta, 1992.

[20] E. Erdem and Y. Soylu, “Age and gender-related change in mathematical reasoning ability and some educational suggestions,” J. Educ. Pract., vol. 8, no. 7, pp. 116-127, 2017.

[21] M. Yolculu, Z. Kuram, B. Me, Z. Kuram, and Z. Kuram, "Investigating students' logical thinking abilities: the effects of gender and grade level,” Hacettepe Üniversitesi Ĕ̆itim Fakültesi Derg., vol. 28, no. 1, pp. 219-225, 2005.

[22] N. Valanides, "Cognitive abilities among twelfth-grade students: Implications for science teaching," Educ. Res. Eval., vol. 3, no. 2, pp. 160-186, 1997, DOI: $10.1080 / 1380361970030204$.

[23] M. Paul and N. Hlanganipai, "The nature of misconceptions and cognitive obstacles faced by secondary school mathematics students in understanding probability: A case study of selected Polokwane secondary schools,” Mediterr. J. Soc. Sci., vol. 5, no. 8, pp. 446-455, 2014, DOI: 10.5901/mjss.2014.v5n8p446.

[24] H. Tsakiridou and E. Vavyla, "Probability concepts in primary school,” Am. J. Educ. Res., vol. 3, no. 4, pp. 535540, 2015, DOI: 10.12691/education-3-4-21.

[25] D. I. Sari, I. K. Budayasa, and D. Juniati, "Probabilistic thinking of elementary school students in solving probability tasks based on math ability,” AIP Conf. Proc., vol. 1867, no. August, pp. 1-6, 2017, DOI: 10.1063/1.4994431.

[26] Zetriuslita, R. Ariawan, and Hayatun Nufus, "Students , Critical Thinking Ability: Description Based on Academic Level and Gender,” J. Educ. Pract., vol. 7, no. 12, pp. 154 164, 2016. 